\title{
Early Treatment with Integrase Inhibitor Achieves a Functional Cure for Pediatric SIV Infection
}

\section{Xiaolei Wang}

Tulane University School of Medicine

\section{Eunice Vincent}

Tulane University School of Medicine

Jiasheng Shao

Tulane University School of Medicine

Hong Lu

Aaron Diamond AIDS Research Center

\section{Summer Siddiqui}

Tulane University School of Medicine

Robert Blair

Tulane University School of Medicine

Xueling Wu

Aaron Diamond AIDS Research Center

Lara A Doyle-Meyers

Tulane University School of Medicine

Kasi E. Russell-Lodrigue

Tulane University School of Medicine

Widade Ziani

Tulane University School of Medicine

Rudolf P. Bohm

Tulane University School of Medicine

\section{Ronald S. Veazey}

Tulane University School of Medicine

Huanbin Xu ( $\nabla$ hxu@tulane.edu )

Tulane Medical School https://orcid.org/0000-0003-1742-0979

\section{Research Article}

Keywords: Newborn, SIV, Early ART, Proviral reservoir, Functional cure

Posted Date: April 16th, 2021 
DOI: https://doi.org/10.21203/rs.3.rs-426657/v1

License: (c) (1) This work is licensed under a Creative Commons Attribution 4.0 International License. Read Full License 
5 Xiaolei Wang ${ }^{1}$, Eunice Vincent ${ }^{1}$, Jiasheng Shao ${ }^{1}$, Hong $\mathrm{Lu}^{2}$, Summer Siddiqui ${ }^{1}$, Robert Blair ${ }^{1}$, Xueling $\mathrm{Wu}^{2}$,

6 Lara A Doyle-Meyers1, Kasi E. Russell-Lodrigue ${ }^{1}$, Widade Ziani ${ }^{1}$, Rudolf P. Bohm ${ }^{1}$, Ronald S. Veazey ${ }^{1}$ and 7 Huanbin $\mathrm{Xu}^{1, *}$

${ }^{1}$ Tulane National Primate Research Center, Tulane University School of Medicine, 18703 Three Rivers Road, Covington, LA 70433, USA;

${ }^{2}$ Aaron Diamond AIDS Research Center, Affiliate of the Columbia University, New York, NY 10016, USA.

*Corresponding author. Email: hxu@tulane.edu

Phone (985) 871-6401

Fax: (985) 871-6510 8 9 (1)

\section{.}


Neonatal HIV infection causes rapid disease progression to end-stage of AIDS if untreated. To date, there are no reported cases of a genuine functional cure in Pediatric AIDS Clinical Trial Group lacking integrase inhibitor regimen, even when initiated early. In this study, three infant rhesus macaques born on the same day were intravenously infected with SIV on the day of birth and received ART containing tenofovir, FTC, and dolutegravir (DTG) initiated 3 days post infection and continued daily for 9 months. The results showed early ART combination effectively suppressed viral replication to undetectable viremia throughout the treatment course. Remarkably, two of three infants showed complete virologic remission and intestinal CD4+ $T$ cell preservation throughout the period of study after analytical treatment interruption (ATI), as well as undetectable cell-associated proviral DNA in PBMCs, axillary lymph nodes (LNs), and rectal biopsies. However, viral rebound was observed in one of the three infants at two months post ATI. Notably, very low levels of integrated proviral SIV DNA were detected in the lymph node of this animal under CART. Sustained virologic remission was achieved in the other two infants despite absence of protective MHC alleles or neutralizing antibody responses. These findings suggest that early integrase inhibitor-based ART, initiated before irreversible proviral reservoir seeding, can completely suppress viral replication and effectively block new viral genome integration, providing a proof of concept that HIV functional cure and possibly a cure is possible, at least in a proportion of infants postnatally infected with HIV.

Keywords: Newborn, SIV, Early ART, Proviral reservoir, Functional cure

\section{Introduction}

Although the Berlin, London, and Düsseldorf adult patients appeared to have experienced a "sterilizing HIV cure" ${ }^{1}$, the treatment regimen involved toxic chemotherapy due to hematological malignancies followed by hematopoietic stem cell transplantation, which is simply not feasible for most patients due to the high risk and expense. In HIV-infected adult patients, proviral reservoirs are rapidly seeded in tissues as early as 2 days post infection ${ }^{2,3}$. In the vast majority of ART-treated patients with HIV, rapid viral rebound is observed

54 following analytic treatment interruption (ATI), albeit existence of considerable HIV-specific antibodies and 
Mother-to-child HIV transmission occurs mainly in utero at late pregnancy, at the time of delivery or via

breastfeeding ${ }^{7,8}$. Although prenatal interventions to prevent vertical transmission have been extremely successful, postnatal HIV infections still occurs during labor or via breastfeeding ${ }^{9}$. Initiation of early ART may restrict proviral reservoir size ${ }^{10,11}$, allowing a key time period for normal immune development and the potential for ART-free virologic remission after treatment interruption. However, early antiretroviral therapy (ART), even initiated as early as within 30 minutes after birth in infants in Pediatric AIDS Clinical Trials, usually fails to achieve a sustained state of ART-free virologic remission, leading to HIV rebound after months or years of treatment interruption ${ }^{12,13,14,15,16}$. For example, attempts at a cure for pediatric HIV patients have failed as the "Mississippi" and "Canadian" cases eventually show viral rebound once treatment was discontinued 12, 13, 14, ${ }^{15,16}$. Note the presence of proviral DNA in tissues of human infants at ART initiation is rarely confirmed due to sample collection limitations, and current treatment strategies (e.g., dual nucleoside reverse transcriptase inhibitors AZT and 3TC, plus proteinase inhibitors) may permit new or continual proviral reservoirs to be established, creating a hurdle towards a pediatric HIV cure. Newborn infants possess a unique immune system, which is distinct from adults and compartmentalized by the "immature" systemic immune system and the "functional/mature" mucosal system ${ }^{17,18}$. The neonates and infants infected with HIV develop disease rapidly, which is accompanied by compromised immune development and function ${ }^{19,20}$. Thus, proviral reservoir seeding in infant HIV infection may be distinct from its process in adults which have larger numbers of potential target cells in tissues.

Small integrated proviral reservoirs, which are established prenatally while resistant to ART, and/or newly seeded under current therapeutic regimens lacking an integrase inhibitor, may become a driving forces for viral persistence. In this study, early 9 month-combined ART containing dolutegravir (DTG) was initiated at 3 days post SIV infection in the three infant rhesus macaques who were born on the same day and infected with SIV on the day of birth. Our data showed that sustained virologic remission had been achieved throughout the period of study, in two of three postnatally SIV-infected infant rhesus macaques using an early DTG-based ART regimen. Collectively, an optimized early ART regimen, initiated prior to proviral reservoir seeding, can potentially achieve a functional cure in a proportion of HIV-infected infants. 
$\boldsymbol{A R T}$. To assess the existence of proviral reservoirs seeded when ART is initiated, and to compare the effects

\section{Cellular viral reservoirs in systemic and lymphoid tissues of SIV-infected infant macaques before and} after analytical treatment interruption. To track proviral reservoir seeding in these infants, we examined the SIV-infected cells from lymph node (LN) and rectal biopsies and measured levels of cell-associated integrated proviral DNA at multiple time points before and after ATI. In situ hybridization analysis indicated that SIV RNA was detected in both LN and rectal tissue of infant 2 after 2 months post ATI, compared with undetectable SIV RNA in both tissues of infants 1 and 3 at this timepoint (Figs. 2A-2F) even SIV RNA was still negative in LNs of infant 1 and 2 at 9 months post ATI (data not shown). Further analysis indicated that cell-associated SIV RNA and proviral DNA were undetectable in PBMCs and LNs of infants 1 and 3 while receiving ART at month 
1, or PBMCs, LNs and rectal tissues of these two animals at 2- and 9-months post ATI. Remarkably, very low levels of proviral DNA (0.406 copies/million cells) were detected in LN of only infant 2 while under ART at month 1, albeit SIV RNA was not detected at this time point in this animal, followed by rapid increase of cellassociated SIV RNA and proviral DNA once treatment is discontinued (Figs. 2G and $\mathbf{2 H}$ ), which was consistent with the emergence of viral rebound and SIV positive cells in the lymphoid tissues post ATI (Figs. 1A, 2A and 2D). Unfortunately, the samples at ART initiation (3 dpi) in these three infants are not available for tracking the presence of proviral DNA. To provide data on proviral reservoir seeding in neonates at 3dpi, we examined cell-associated viral RNA and integrated proviral DNA in archived lymphocytes from blood, spleen and jejunum at this key timepoint in two additional SIV-infected infants. We did not detect proviral DNA in peripheral and lymphoid tissues at least in these two infants by 3dpi, despite cell-associated SIV RNA was still detectable in all tissues examined (Fig. 2I). These findings suggest that small proviral reservoirs, once seeded at an early stage of HIV infection, may be resistant to ART, and that their persistence imposes a high risk of viral rebound when treatment is stopped.

\section{Histopathological examination of lymph nodes and rectal biopsies of SIV-infected infant macaques} before and after analytical treatment interruption. Given that two of three infants on early ART achieved what appears to be complete viral remission and one did not, potential correlates of protection behind of this finding were explored including potential pathologic changes in LN and rectal tissues, resistant MHC I alleles, anti-Env /neutralizing antibodies, and SIV-specific CD8+ T cells. We previously reported that SIV infection in newborn macaques inhibits follicle and germinal center formation evident by 1-month post infection, resulting in impaired antibody responses ${ }^{21}$. Histopathological analysis of LNs did not demonstrate differences among the experimental infants, but LN tissue in infant 2 at 1 month after early ART, in which lymphoid follicles rarely contained small and reduced germinal centers with low numbers of histiocytes in the medullary sinuses, and the corticomedullary junction was infiltrated by low to moderate numbers of neutrophils (Figs. 3A-3H). There were multifocal aggregates of neutrophils and adjacent crypts contained degenerate neutrophils (crypt abscesses) in rectum in infant 2 post ATI (Fig. 3I). In infants 1 and 3 before and after ATI, the LN cortex was expanded by multifocal paracortical hyperplasia with low numbers of histiocytes in the medullary sinuses, and the jejunum lamina propria was infiltrated by low numbers of lymphocytes and plasma cells (Figs. 3A-3M), 
which has been frequently observed in animals on daily drug treatment by intramuscular injection.

Correlates of immunity in SIV-infected infant macaques with sustained virological remission. To explore the protective mechanisms in two infants, we examined the MHC I alleles, SIV-specific CTLs and anti-SIV neutralizing antibody responses. As indicated in Fig. 4A, these three infants were negative for three key MHC I alleles (Mamu-A*01, Mamu-B*08 and Mamu-B*017, the latter two MHC genotypes are respectively equivalent to HLA-B27 and HLA-B57 in humans) that, if present, are associated with elite control in SIV-infected rhesus macaques ${ }^{22}$. Also, anti-SIV gp140 antibodies (Abs) and SIV gag-specific CD8+ T cells were detected in only infant 2 when the viral rebound was observed at 2 months of ATI. In contrast, neither anti-SIV gp140 Abs nor CTLs were detected in infants 1 and 3, who showed sustained virological remission (Figs. 4B \& 4C). Further, neutralizing Abs against SIV Env were not elicited in any of the three postnatally SIV-infected infant macaques on early ART (Fig. 4D). Combined, these findings demonstrate that sustained virologic remission in these two infants is not associated with a protective MHC genotype, nAb or CTL responses. virologic remission is achieved in a proportion of postnatally SIV-infected infant macaques on early DTG-based ART.

Given a unique immune system in developing neonatal infants, viral susceptibility, viral reservoir establishment, and immune responses in neonates exposed to HIV might differ from those in adults ${ }^{19,20}$. All children exposed to HIV before, during, and after birth should receive early antiretroviral (ARV) drugs to reduce the risk of HIV acquisition, morbidity, and mortality ${ }^{10,15,20,26,27}$. Since interventions to prevent mother-to-child transmission (MTCT) have been extremely successful ${ }^{28,29}$, new HIV infection in infants mostly occurs at delivery or via breastfeeding. The early ART regimen currently administered in infants is a combination of dual-NRTI 
$(\mathrm{AZT}+3 \mathrm{TC})$ with protease inhibitors $(\mathrm{LPV} / \mathrm{r})$, yet this regimen may not effectively prevent new or continual viral integration and proviral reservoir seeding in infants postnatally or perinatally infected with HIV. Another therapeutic option, DTG, is a very well-tolerated, highly effective, and affordable INSTI drug in low- and middleincome countries ${ }^{30}$, and achieves more rapid and complete viral suppression compared to dolutegravir ${ }^{31}$. Although a study in Botswana shows that DTG used in the early first trimester of pregnancy may be associated with the incidence of neural tube defects (NTDs) in newborns ${ }^{32}$, whereas additional data from this cohort also indicate the risk may only be slightly greater over any non-DTG ART ${ }^{33}$. In general, worldwide pharmacovigilance data do not provide strong support concerning the relationship between NTDs and DTG ${ }^{34,}$ ${ }^{35}$ and irrelevant to postnatally HIV-infected infants. DTG is being studied and introduced in infant HIV treatment practice in the International Maternal Pediatric Adolescent AIDS Clinical Trial (IMPAACT) ${ }^{36}$. DTG was thereby combined with two NRTIs (TFV and FTC) in an early treatment regimen in this study.

Immediate initiation of ART, ideally within hours after birth, may restrict viral reservoir size, maintain normal neonatal immune development and possibly provide opportunities for drug-free, off-ART control ${ }^{10,11,15,24,26,27,}$ 37, 38. However, in the Pediatric AIDS Clinical Trials and cases, including Mississippi and Canadian babies, South African Children with HIV Early Antiretroviral Therapy (CHER) trial, IMPAACT, Pediatric Early HAART and Strategic Treatment Interruption Study (PEHSS), Botswana and European Pregnancy and Pediatric HIV Cohort Collaboration (EPPICC) study, there is no case reported to achieve a functional cure in the HIV+ infants treated by early ART (immediate treatment to several years of age). Unfortunately, the eventual viral rebound is observed once treatment is discontinued ${ }^{11,12,13,14,16,20,23,24,25,39}$. Our study demonstrates that pediatric HIV remission is possible in a proportion of postnatally SIV-infected infants by early ART combined with DTG, an outcome that has not been observed in HIV-infected human adults or SIV-infected macaque adults on early ART $2,4,40,41$. These findings have also not been replicated in SIV-infected infants receiving the same combination of ART yet initiated at 35 dpi or 12 weeks post infection ${ }^{42,43}$. Conceivably, even small integrated proviral reservoirs established in anatomic tissues when ART is initiated ${ }^{15,44,45,46,47}$, while difficult to eradicate by early ART, are likely contribute to viral rebound ATI. Due to limitations in sample collection in infants, proviral DNA at the initiation of early ART, even in blood, has not been fully evaluated or confirmed in these pediatric AIDS clinical trials and cases. These proviral reservoirs may already exist in infants because of perinatal HIV infection, e.g., in utero infection. Further, early ART in these clinical trials and cases, essentially 
applied by LPV/r-based regimen with lack of combination of integrase inhibitors, might not effectively block viral genome integration and subsequent new proviral reservoir seeding in infants. All of these reasons might explain why early ART initiation does not show curative effects in infants perinatally exposed to HIV, underlining the need to diagnose tissue proviral reservoirs in infants at the initiation of ART, and to include integrase inhibitors with the cART strategy.

The intrinsic features of pediatric HIV remission may be multifactorial and likely involve immune maturation status, ontogeny, susceptibility, host genetics in infants and maternal factors ${ }^{20}$. Previous studies report that a small fraction of the HIV-infected infants develops de novo potent and broadly neutralizing antibodies (bnAbs) that respond to different and perhaps new epitopes of HIV-1 Env as early as one year post infection ${ }^{48}$, compared with bnAbs developed in HIV+ adults after 2-3 years of infection ${ }^{49}$. However, neutralizing Abs against SIV Env were not detected in any of the three postnatally SIV-infected infant macaques on early ART, likely because SIV Env does not typically elicit nAbs, and if so, with a substantial delay and at lower titers ${ }^{50}$. However, the protective mechanisms of discrepant outcomes in these infant macaques still remain elusive.

In summary, establishment of small irreversible proviral reservoirs before early ART initiation may probably determine HIV persistence and the risk of viral rebound after treatment interruption, as indicated by very low levels of LN proviral DNA under ART, and subsequent delayed while eventual viral rebound in infant 2. Early ART combined with an integrase inhibitor, applied before proviral reservoir seeding, may prevent new viral genome integration, thereby suppressing viral replication, blocking new or continual proviral reservoir seeding, and eliminating existing viral reservoirs. Our findings provide of proof of concept that pediatric functional cure is possible at least in a proportion of infants postnatally infected with HIV, especially those infected around the time of delivery which is of great significance for normal immune development and achieving a truly functional cure for pediatric HIV infection.

\section{Methods}

\section{Ethics statement}

All animals in this study were housed at the Tulane National Primate Research Center in accordance with the Association for Assessment and Accreditation of Laboratory Animal Care International standards. All studies were reviewed and approved by the Tulane University Institutional Animal Care and Use Committee under 
protocol number P0401. Animal housing and studies were carried out in strict accordance with the recommendations in the Guide for the Care and Use of Laboratory Animals of the National Institutes of Health $(\mathrm{NIH}, \mathrm{AAALAC} \# 000594)$ and with the recommendations of the Weather all report; "The Use of Non-Human Primates in Research". All clinical procedures were carried out under the direction of a laboratory animal veterinarian. All procedures were performed under anesthesia using ketamine, and all efforts were made to minimize stress, improve housing conditions, and to provide enrichment opportunities (e.g., objects to manipulate in cage, varied food supplements, foraging and task-oriented feeding methods, interaction with caregivers and research staff).

\section{Animals and virus}

Three newborn, Indian-origin rhesus macaques (Macaca mulatta, born on the same day) were intravenously inoculated with 100 TCID50 SIVmac251 after birth (<24h, day 0). At day 3, these animals received combined antiretroviral treatment (CART) with 3 anti-HIV drugs [tenofovir (TFV), $20 \mathrm{mg} / \mathrm{kg} /$ day; emtricitabine (FTC), 30 $\mathrm{mg} / \mathrm{kg} /$ day; and dolutegravir (DTG), at $2.5 \mathrm{mg} / \mathrm{kg} /$ day] for 9 months. TFV and FTC were kindly provided by Gilead Inc. (Foster city, CA), and DTG was kindly provided by ViiV Healthcare (Research Triangle, NC). Blood were collected weekly or monthly, lymph node biopsies collected at 1 month of early ART, 2 and 9 months of treatment interruption, and rectal biopsies collected at 2 and 9 months of treatment interruption. A complete set of tissues were collected at necropsy if viremia rebound was observed. Plasma and single-cell suspensions were prepared to examine plasma viral load and integrated viral DNA and for flow cytometry analysis. Archived samples from infant macaques $(n=12)$, which were intravenously inoculated with 100 TCID50 SIVmac251 after birth within $24 \mathrm{~h}$, were analyzed to compare plasma viral load and the percentage of peripheral CD4+ T cells $(n=9)$ or to measure cell-associated SIV RNA and proviral DNA in tissues at 3 days post SIV inoculation $(n=3)$. In addition, archived rectal lymphocytes from age-matched SIV naïve infants ( $\mathrm{n}=6,1-2$ years old) were used for the comparative analysis of post ATI rectal CD4+ T cells in the three experimental infants of the current study.

\section{Tissue collection and phenotyping}

Fresh cells isolated from blood were stained and analyzed by flow cytometry as we previously reported ${ }^{21}$. Cells were stained with: CD3 (SP34), CD4 (OKT4, BioLegend), CD8 (SK1), CD28 (28.2), CD95 (DX2) and LIVE/DEAD Fixable Aqua Dead Cell Stain Kit (Invitrogen, Grand Island, NY). Isotype-matched controls were included in all experiments. All antibodies and reagents were purchased from BD Biosciences Pharmingen 
(San Diego, CA) unless otherwise noted. Samples were resuspended in BD Stabilizing Fixative (BD Biosciences) and acquired on a FACS FORTESSA (Becton Dickinson, San Jose, CA). Data were analyzed with FlowJo software (Tree Star, Ashland, OR).

\section{Genomic DNA and total RNA extraction}

Fresh single cells, isolated from EDTA-treated venous blood by density gradient centrifugation with Lymphocyte Separation Medium (MP Biomedicals, Santa Ana, CA) or lymph node and rectal biopsies, which were then processed to extract total genomic DNA and cellular RNA with a AllPrep DNA/RNA Mini Kit (Qiagen) according to the manufacturer's instructions. Viral RNA in plasma was directly isolated using the QIAamp Viral RNA Mini Kit (Qiagen). The extracted DNA and RNA samples were stored at $-80^{\circ} \mathrm{C}$ until further processing.

\section{Quantification of plasma viral load and cell-associated SIV RNA transcripts}

Plasma viral loads and cell-associated SIV RNA/DNA were measured by specific primer sets and probes as previously described ${ }^{51}$. Briefly, the extracted RNA was reverse-transcribed into cDNA using a SuperScript III first-strand synthesis system (Invitrogen) in a thermocycler at $25.0^{\circ} \mathrm{C}$ for $5 \mathrm{~min}$ and $50.0^{\circ} \mathrm{C}$ for $60 \mathrm{~min}$, followed by an enzyme inactivation step at $70.0^{\circ} \mathrm{C}$ for $15 \mathrm{~min}$. cDNA from cell-derived RNA was further used to quantify different unspliced SIV transcripts by digital droplet PCR (QX100 Droplet Digital qPCR system, Bio-Rad). Samples were run in duplicate in a $20 \mu \mathrm{L}$ volume containing Supermix, $250 \mathrm{nM}$ primers, $900 \mathrm{nM}$ probe and 2 $\mu \mathrm{L}$ undiluted cDNA under the following cycling conditions: $10 \mathrm{~min}$ at $95^{\circ} \mathrm{C}, 40$ cycles of $94^{\circ} \mathrm{C} / 30 \mathrm{~s}$ and $63^{\circ} \mathrm{C} / 60 \mathrm{~s}$, and a final step at $98^{\circ} \mathrm{C}$ for $10 \mathrm{~min}$. Droplets were analyzed by the QuantaSoft software in absolute quantification mode. Copies of SIV transcripts, expressed as copies per 1 million cells, were measured and normalized to cellular input, as determined by copies of genomic CCR5 (single-copy rhesus macaque CCR5 DNA per cell) ${ }^{41}$. The limit of detection (LOD) was based on three or more replicates and calculated using GenEx 5 (www.multid.se).

To quantify integrated proviral DNA, two-step PCR was run in parallel to quantify all viral DNA as previously described ${ }^{51}$. In brief, the pre-amplification reactions were performed using SIV long terminal repeat primer and two outward Alu primers on a 7900HT Sequence Detectorion System (Life Technologies). The reaction conditions were performed as follows: each $25 \mu \mathrm{L}$ of reaction mix, contained 1X PCR buffer, 0.2 mM dNTPs, 2 
$\mathrm{mM} \mathrm{MgCl}, 0.8 \mu \mathrm{M}$ of each primers and 0.5 U Taq DNA polymerase (Invitrogen Life Technologies) and was run for a 5 -minute hot start at $95^{\circ} \mathrm{C}$, followed by 20 cycles of denaturation at $95^{\circ} \mathrm{C}$ for 30 seconds, annealing at $63^{\circ} \mathrm{C}$ for 30 seconds and extension at $72^{\circ} \mathrm{C}$ for 3 minutes. Next, $2.5 \mu \mathrm{L}$ of each amplicon was further amplified in triplicate by real-time PCR reaction using 40 cycles at $95^{\circ} \mathrm{C}$ for 15 seconds and $63^{\circ} \mathrm{C}$ for 1 minute. Highly reproducible calibration curves were generated by plotting $\mathrm{Cq}$ values against log-transformed concentrations of serially diluted standard. Internal standard curves were generated using known copy numbers of target plasmids (1-500 copies) diluted in cellular DNA from SIV naïve rhesus macaques. The calibration curves and intrenal regression curves were used for interpolating initial copies of each target in unknown samples. A nontemplate control (NTC) and extracted cellular DNA from the HUT78/SIVmac239 cell line (positive control) were included in the qPCR reactions. Quantification of integrated proviral DNA was expressed as copies per 1 million cells, in which cell numbers were determined by copies of genomic CCR5 DNA per cell.

\section{Detection of SIV RNA by in situ hybridization}

To identify the SIV RNA in LN and rectal biopsies, formalin-fixed, paraffin-embedded sections (5- $\mu$ m thickness) were cut and adhered to sialinized glass slides. After deparaffinization in xylene, and dehydration with $50 \%$, $70 \%$ and $100 \%$ ethanol, sections were subjected to an RNAscope assay with RNAscope2.5 HD Detection Reagent-Red (ACD) following the manufacturer's instructions. The slides were denatured at $60^{\circ} \mathrm{C}$ for $1 \mathrm{~h}$ and incubated with pre-warmed $\left(60^{\circ} \mathrm{C}\right)$ SIV gag-pol sense probe (ACD) with an additional incubation for $4 \mathrm{~h}$ at $40^{\circ} \mathrm{C}$. The signal was then amplified by Amp1 to Amp6 and identified on tissue sections using a Zeiss digital slide scanner system.

\section{Measurement of SIV gag-specific CD8+ T cells in blood}

SIV gag-specific CD8+ T cells were detected as we previously described ${ }^{52}$. In brief, PBMCs were stimulated by a pool of 15-mer gag peptides (5 $\mathrm{gg} / \mathrm{ml}$ each peptide), medium only (negative control), or phorbol-12myristate-13-acetate (PMA, $5 \mathrm{ng} / \mathrm{ml}$, Sigma) plus ionomycin $(50 \mu \mathrm{g} / \mathrm{ml})$ (positive control) for $6 \mathrm{~h}$. The cultures also contained brefeldin A (Sigma) and $1 \mu \mathrm{g} / \mathrm{ml}$ anti-CD49d and anti-CD28 co-stimulatory molecules (BD Biosciences). Cultured cells were stained with monoclonal antibodies specific for surface molecules of interest (CD3, CD4, CD8) and LIVE/DEAD Cell Staining Kit. After fixation and permeabilizaion with Cytofix/Cytoperm solution (BD Biosciences), cells were further stained with antibodies specific for IFN-y (clone 4S.B3), and TNF- 
$\alpha$ (clone MAB11) and washed by Perm/Wash Buffer (BD Biosciences). Finally, labeled cells were fixed in $1.5 \%$ paraformaldehyde, acquired with a FACSA Verse Cytometer (Becton Dikinson, San Jose, CA), and analyzed using FlowJo software (Tree Star, Ashland, OR). The background level of cytokine staining varied within different samples and different cytokine patterns but was typically $<0.05 \%$ of total CD8+ $T$ cells (median, $0.01 \%)$. Only samples in which the percentage of cytokine-staining cells was at least twice that of background were considered positive.

\section{ELISA}

As previously described ${ }^{21}$, ELISA plates were coated with SIVmac239 gp140 (Immune Tech, New York, NY) at $5 \mu \mathrm{g} / \mathrm{mL}$ in PBS at $4{ }^{\circ} \mathrm{C}$ overnight. After blocking with $1 \%$ BSA in PBS at $37^{\circ} \mathrm{C}$ for 1 hour, serially diluted plasma was incubated on plate at $37^{\circ} \mathrm{C}$ for 1 hour. Horseradish peroxidase (HRP)-conjugated goat antihuman IgA+lgG+lgM (Jackson ImmunoResearch Laboratories, Inc., West Grove, PA) was added at $37^{\circ} \mathrm{C}$ for 1 hour. All volumes were $100 \mu \mathrm{L} /$ well, except $200 \mu \mathrm{L} /$ well for blocking. Plates were washed between each step with $0.1 \%$ Tween 20 in PBS, developed with 3,3',5,5'-tetramethylbenzidine (TMB) (Kirkegaard \& Perry Laboratories), and read at $450 \mathrm{~nm}$.

\section{SIV neutralization antibody assay}

SIV neutralization was measured using single-round infection of TZM-bl cells with Env pseudoviruses as described ${ }^{53}$. Briefly, $40 \mu \mathrm{L}$ of virus was incubated for $30 \mathrm{~min}$ at $37^{\circ} \mathrm{C}$ with $10 \mu \mathrm{L}$ of serially diluted plasma in duplicate wells before the addition of TZM-bl cells. To maintain consistent assay conditions, sham medium was used in place of plasma in specified control wells. Plasma dilutions were defined at the point of incubation with virus supernatant. Virus infection levels were determined after 2 days by a luciferase assay (Promega, Madison, WI). Neutralization curves were fitted by the 5-parameter nonlinear regression built in Prism 8.0 (GraphPad Software, La Jolla, $C A$ ), and $50 \%$ inhibitory dilutions $\left(\mathrm{ID}_{50}\right)$ were defined as the plasma reciprocal dilutions required to inhibit viral infection by $50 \%$.

Author Contributions: X.Wang, E.V., S.J., H.L., S.S., R.B., X.Wu, L.D.M., K.E.R., W.Z. collected data. R.B.R., R.S.V. contributed to data interpretation and revisions. H.X. and X.W. designed the experiments, data analysis and wrote the manuscript. 
Acknowledgments: We thank Meagan Watkins for technical support and veterinarians for animal care. This work was supported by the NIH grants R01 DE025432, R01 Al147372, R01 HD099857, and the Office of Research Infrastructure Programs (ORIP) of the National Institutes of Health through grant no. OD011104-51.

Competing Interests: The authors declare no competing financial interests.

\section{References}

1. Kalidasan V, Theva Das K. Lessons Learned From Failures and Success Stories of HIV Breakthroughs: Are We Getting Closer to an HIV Cure? Front Microbiol 11, 46 (2020).

2. Henrich TJ, et al. HIV-1 persistence following extremely early initiation of antiretroviral therapy (ART) during acute HIV-1 infection: An observational study. PLoS Med 14, e1002417 (2017).

3. Whitney JB, et al. Prevention of SIVmac251 reservoir seeding in rhesus monkeys by early antiretroviral therapy. Nat Commun 9, 5429 (2018).

4. Ananworanich J, et al. HIV DNA Set Point is Rapidly Established in Acute HIV Infection and Dramatically Reduced by Early ART. EBioMedicine 11, 68-72 (2016).

5. Pierson T, McArthur J, Siliciano RF. Reservoirs for HIV-1: mechanisms for viral persistence in the presence of antiviral immune responses and antiretroviral therapy. Annu Rev Immunol 18, 665-708 (2000).

6. Collins DR, Gaiha GD, Walker BD. CD8(+) T cells in HIV control, cure and prevention. Nat Rev Immunol 20, 471-482 (2020).

7. Collins IJ, Judd A, Gibb DM. Immediate antiretroviral therapy in young HIV-infected children: benefits and risks. Curr Opin HIV AIDS 9, 87-94 (2014).

8. Faye A. Early antiretroviral treatment of infants to attain HIV remission: Not just a matter of timing. EClinicalMedicine 20, 100284 (2020).

9. Rollins N, Mahy M, Becquet R, Kuhn L, Creek T, Mofenson L. Estimates of peripartum and postnatal mother-to-child transmission probabilities of HIV for use in Spectrum and other population-based models. Sex Transm Infect 88 Suppl 2, i44-51 (2012).

10. Luzuriaga $\mathrm{K}$, et al. HIV type 1 (HIV-1) proviral reservoirs decay continuously under sustained virologic control in HIV-1-infected children who received early treatment. $J$ Infect Dis 210, 1529-1538 (2014).

11. Garcia-Broncano $\mathrm{P}$, et al. Early antiretroviral therapy in neonates with HIV-1 infection restricts viral reservoir size and induces a distinct innate immune profile. Sci Trans/ Med 11, (2019).

12. Persaud $\mathrm{D}$, et al. Absence of detectable HIV-1 viremia after treatment cessation in an infant. $N$ Engl $J$ Med 369, 1828-1835 (2013).

13. Giacomet V, et al. No cure of HIV infection in a child despite early treatment and apparent viral clearance. Lancet 384, 1320 (2014). 
14. Butler $\mathrm{KM}$, et al. Rapid viral rebound after 4 years of suppressive therapy in a seronegative HIV-1 infected infant treated from birth. Pediatr Infect Dis J 34, e48-51 (2015).

15. Martinez-Bonet $\mathrm{M}$, et al. Establishment and Replenishment of the Viral Reservoir in Perinatally HIV-1infected Children Initiating Very Early Antiretroviral Therapy. Clin Infect Dis 61, 1169-1178 (2015).

16. Ateba Ndongo $\mathrm{F}$, et al. Virologic Response to Early Antiretroviral Therapy in HIV-infected Infants: Evaluation After 2 Years of Treatment in the Pediacam Study, Cameroon. Pediatr Infect Dis J 37, 78-84 (2018).

17. Wang $X$, et al. Massive infection and loss of CD4+ T cells occurs in the intestinal tract of neonatal rhesus macaques in acute SIV infection. Blood 109, 1174-1181 (2007).

18. Wang $X$, et al. Simian immunodeficiency virus selectively infects proliferating CD4+ T cells in neonatal rhesus macaques. Blood 116, 4168-4174 (2010).

19. Muenchhoff M, Prendergast AJ, Goulder PJ. Immunity to HIV in Early Life. Front Immunol 5, 391 (2014).

20. Goulder PJ, Lewin SR, Leitman EM. Paediatric HIV infection: the potential for cure. Nat Rev Immunol 16, 259-271 (2016).

21. $\mathrm{Xu} \mathrm{H}$, et al. Impaired Development and Expansion of Germinal Center Follicular Th Cells in Simian Immunodeficiency Virus-Infected Neonatal Macaques. J Immunol 201, 1994-2003 (2018).

22. Loffredo JT, et al. Patterns of CD8+ immunodominance may influence the ability of Mamu-B*08positive macaques to naturally control simian immunodeficiency virus SIVmac239 replication. $J$ Virol 82, 1723-1738 (2008).

23. Prendergast $A$, et al. Early virological suppression with three-class antiretroviral therapy in HIV-infected African infants. AIDS 22, 1333-1343 (2008).

24. Cotton MF, et al. Early time-limited antiretroviral therapy versus deferred therapy in South African infants infected with HIV: results from the children with HIV early antiretroviral (CHER) randomised trial. Lancet 382, 1555-1563 (2013).

25. Luzuriaga $\mathrm{K}$, et al. Viremic relapse after HIV-1 remission in a perinatally infected child. N Engl J Med 372, 786-788 (2015).

26. Ananworanich J, et al. Reduced markers of HIV persistence and restricted HIV-specific immune responses after early antiretroviral therapy in children. AIDS 28, 1015-1020 (2014).

27. van Zyl GU, Bedison MA, van Rensburg AJ, Laughton B, Cotton MF, Mellors JW. Early Antiretroviral Therapy in South African Children Reduces HIV-1-Infected Cells and Cell-Associated HIV-1 RNA in Blood Mononuclear Cells. J Infect Dis 212, 39-43 (2015).

28. Barral MF, de Oliveira GR, Lobato RC, Mendoza-Sassi RA, Martinez AM, Goncalves CV. Risk factors of HIV-1 vertical transmission (VT) and the influence of antiretroviral therapy (ART) in pregnancy outcome. Rev Inst Med Trop Sao Paulo 56, 133-138 (2014).

29. Fowler MG, et al. Benefits and Risks of Antiretroviral Therapy for Perinatal HIV Prevention. $N$ Engl $J$ Med 375, 1726-1737 (2016). 
30. Alhassan $\mathrm{Y}$, et al. Engendering health systems in response to national rollout of dolutegravir-based regimens among women of childbearing potential: a qualitative study with stakeholders in South Africa and Uganda. BMC Health Serv Res 20, 705 (2020).

31. Dorward J, et al. Dolutegravir for first-line antiretroviral therapy in low-income and middle-income countries: uncertainties and opportunities for implementation and research. Lancet HIV 5, e400-e404 (2018).

32. Zash R, Makhema J, Shapiro RL. Neural-Tube Defects with Dolutegravir Treatment from the Time of Conception. N Engl J Med 379, 979-981 (2018).

33. Zash R, et al. Neural-Tube Defects and Antiretroviral Treatment Regimens in Botswana. N Engl J Med 381, 827-840 (2019).

34. Rahimi S. Dolutegravir becomes first choice for HIV. Lancet Infect Dis 19, 937-938 (2019).

35. Chouchana L, Pariente A, Pannier E, Tsatsaris V, Treluyer JM. Dolutegravir and neural tube defects: a new insight. Lancet Infect Dis 20, 405-406 (2020).

36. Penazzato $M$, et al. Prioritising the most needed paediatric antiretroviral formulations: the PADO4 list. Lancet HIV 6, e623-e631 (2019).

37. Violari A, et al. Early antiretroviral therapy and mortality among HIV-infected infants. N Engl J Med 359, 2233-2244 (2008).

38. Rainwater-Lovett K, Luzuriaga K, Persaud D. Very early combination antiretroviral therapy in infants: prospects for cure. Curr Opin HIV AIDS 10, 4-11 (2015).

39. Kuhn L, et al. Early antiretroviral treatment of infants to attain HIV remission. EClinicalMedicine 18, 100241 (2020).

40. Whitney JB, et al. Rapid seeding of the viral reservoir prior to SIV viraemia in rhesus monkeys. Nature 512, 74-77 (2014).

41. Okoye AA, et al. Early antiretroviral therapy limits SIV reservoir establishment to delay or prevent posttreatment viral rebound. Nat Med 24, 1430-1440 (2018).

42. Mavigner M, et al. Correction for Mavigner et al., "Simian Immunodeficiency Virus Persistence in Cellular and Anatomic Reservoirs in Antiretroviral Therapy-Suppressed Infant Rhesus Macaques". J Virol 94, (2020).

43. Goswami R, et al. Analytical Treatment Interruption after Short-Term Antiretroviral Therapy in a Postnatally Simian-Human Immunodeficiency Virus-Infected Infant Rhesus Macaque Model. mBio 10, (2019).

44. Williams JP, et al. HIV-1 DNA predicts disease progression and post-treatment virological control. Elife 3, e03821 (2014).

45. Luzuriaga K. Early Combination Antiretroviral Therapy Limits HIV-1 Persistence in Children. Annu Rev Med 67, 201-213 (2016).

46. Simonetti FR, et al. Intact proviral DNA assay analysis of large cohorts of people with HIV provides a benchmark for the frequency and composition of persistent proviral DNA. Proc Natl Acad Sci U S A $117,18692-18700$ (2020). 
47. Clarridge KE, et al. Effect of analytical treatment interruption and reinitiation of antiretroviral therapy on HIV reservoirs and immunologic parameters in infected individuals. PLoS Pathog 14, e1006792 (2018).

48. Goo L, Chohan V, Nduati R, Overbaugh J. Early development of broadly neutralizing antibodies in HIV1-infected infants. Nat Med 20, 655-658 (2014).

49. Anthony C, et al. Cooperation between Strain-Specific and Broadly Neutralizing Responses Limited Viral Escape and Prolonged the Exposure of the Broadly Neutralizing Epitope. J Virol 91, (2017).

50. Yeh WW, et al. Autologous neutralizing antibodies to the transmitted/founder viruses emerge late after simian immunodeficiency virus SIVmac251 infection of rhesus monkeys. J Virol 84, 6018-6032 (2010).

51. Ziani W, et al. Increased proviral DNA in circulating cells correlates with plasma viral rebound in SIVinfected rhesus macaques after antiretroviral therapy interruption. $J$ Virol, (2021).

52. Xu H, Wang X, Lackner AA, Veazey RS. CD8 down-regulation and functional impairment of SIVspecific cytotoxic $T$ lymphocytes in lymphoid and mucosal tissues during SIV infection. J Leukoc Biol 93, 943-950 (2013).

53. Ziani W, et al. Immune responses and viral persistence in SHIV.C.CH848-infected rhesus macaques. $J$ Virol, (2021). 
Figure Legends

Figure 1. Virologic and immunologic events in postnatally SIV-infected infant macaques on early ART.

(A) Plasma viral load in three infants on ART initiated at $3 \mathrm{dpi}$, compared with that of archived SIV-infected infants without treatment (solid dark line, $n=9$ ). Two infants on early ART showed sustained virologic remission up to 14 months until the present after treatment interruption. (B) Changes in peripheral CD4+ $T$ cells in the three experimental infants, compared with those of archived SIV-infected infants without treatment (solid dark line, $n=9$ ). Peripheral CD4+ T cell loss was observed in infant 2 at 2 months post ATI. (C) Changes in rectal CD4+ T cells in three infants at 2- or 9-months post ATI, compared with additional those of age-matched SIV naïve infants with 1-2 years old ( $n=6)$. (D) Representative dot plot of central memory CD4+ T cells in the blood of three experimental infants at 2 months post ATI, compared with age-matched SIV naïve control. (E) Months of viral rebound after treatment interruption in postnatally SIV-infected infants when ART is initiated at 3dpi $(n=3)$. (F) Survival of postnatally SIV-infected infants with $(n=2)$ or without $(n=9)$ early ART. The three experimental infants were born on the same day and intravenously inoculated with the same SIV inoculum after birth and received DTG-based ART (TFV/FTC/DTG) initiated at 3 dpi for 9 months. Infant 2 was euthanized at 2 months post ATI when viral rebound was observed.

Figure 2. In situ SIV RNA in LN and rectal biopsies and cell-associated SIV RNA and proviral DNA in postnatally SIV-infected infant macaques on early ART. (A-C) In situ SIV RNA+ cells in LNs in three infants at 2 months post ATI. (D-F) In situ SIV RNA+ cells in rectal tissue biopsies in three infants at 2 months post ATI. SIV RNA was detected in both LN and rectal tissue of only infant 2 at 2 months post ATI (A and D). (G) Levels of cell-associated SIV RNA in PBMCs and LNs at month 1 under ART, or PBMCs, and LN and rectal 
555 lymphocytes at 2-, 9-months post ATI. (H) Levels of cell-associated SIV integrated proviral DNA in PBMCs and

556 LNs at month 1 under ART, or PBMCs, and LN and rectal lymphocytes at 2-, 9-months post ATI. Notably, very

557 low levels of proviral DNA (0.406 copies/million cells) were detected in the LN of only infant 2 but not infants 1 and 3 at month 1 of ART. (I) Levels of cell-associated SIV RNA and proviral DNA in archived PBMCs, spleen and jejunum lamina propria lymphocytes in two additional SIV-infected neonates, who were intravenously infected with SIV at birth without treatment and euthanized at 3 dpi. Bar, 100 $\mathrm{mm}$.

Figure 3. Histopathological changes of axillary LN and rectal tissues in postnatally SIV-infected infant macaques on early ART. (A-H) H\&E staining of LN in experimental infants at 1 month under ART (A-C), 2months (D-F) or 9-months (G and H) post ATI. (I-M) H\&E staining of rectal tissues in experimental infants at 2 $(\mathrm{I}-\mathrm{K})$ or $9(\mathrm{~L}$ and $\mathrm{M})$ months post ATI. There were no differences among the three infants, except in infant 2 at 1 month under ART, which showed small and limited numbers of germinal centers in the LN and multifocal aggregates of neutrophils in the rectum at month 2 of ATI. Infant 2 was euthanized at 2 months of ATI when viral rebound was observed. Bar, $200 \mu \mathrm{m}$.

Figure 4. SIV Env-specific antibody and SIV gag-specific CTL responses in postnatally SIV-infected infant macaques on early ART. (A) MHC I alleles in the three experimental infants. (B) SIV gag-specific CD8+ T cells in the three infants at 2 months post ATI. (C) Levels of anti-SIV gp140-specific antibodies in the three infants before and after treatment interruption. (D) Levels of neutralizing antibody against SIV Env in the three infants before and after treatment interruption ATI. SIV gag-specific CTLs and anti-SIV Env antibody were detected in only infant 2 at 2 months post ATI when viral rebound was observed. None of the three infants had protective MHC class I alleles $\left(\right.$ Mamu- $B^{*} 08$, Mamu- $A^{*} 01$, or Mamu- $\left.B^{*} 17\right)$ or exhibited neutralizing antibody responses. 

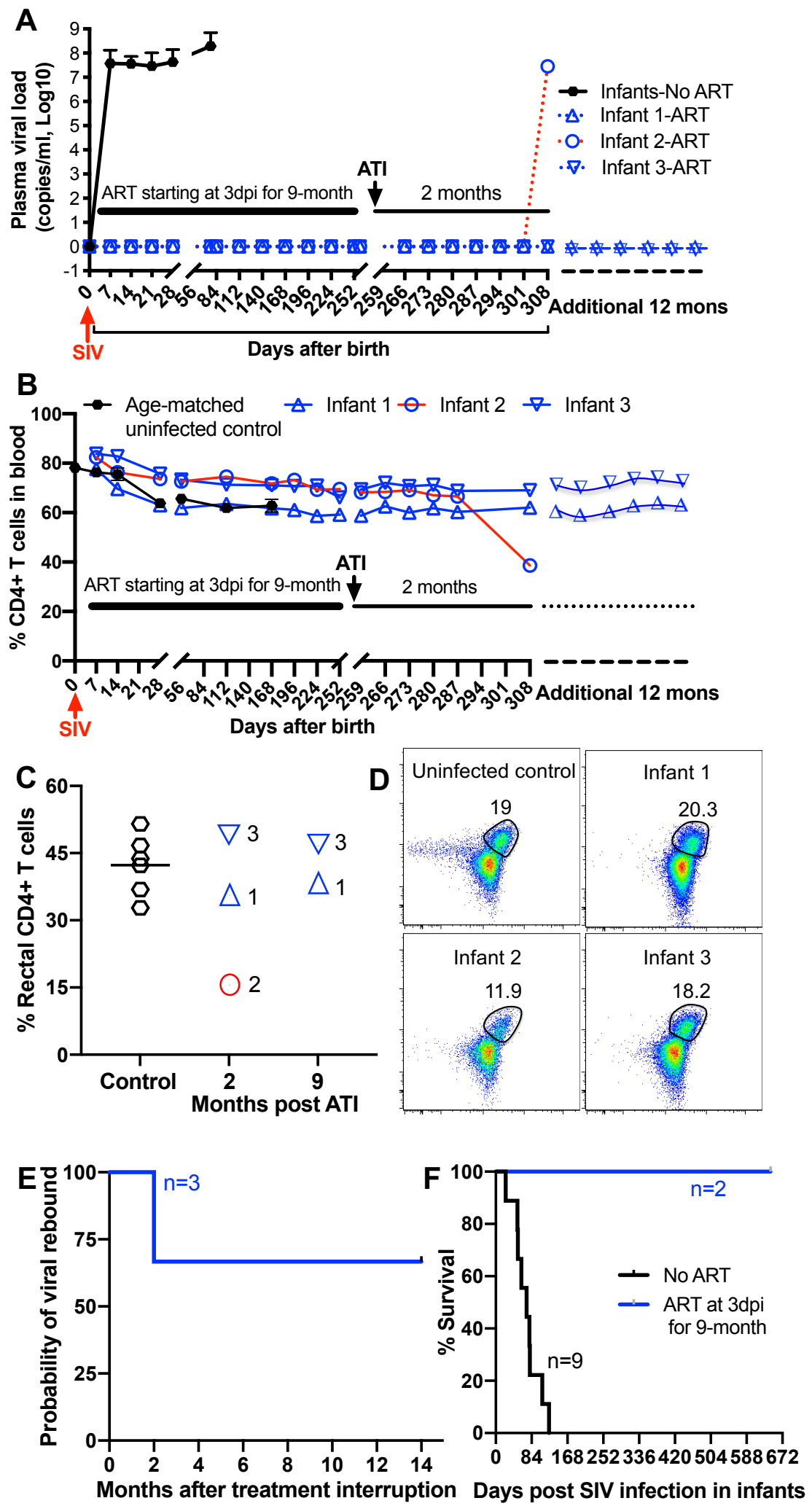
Infant 2
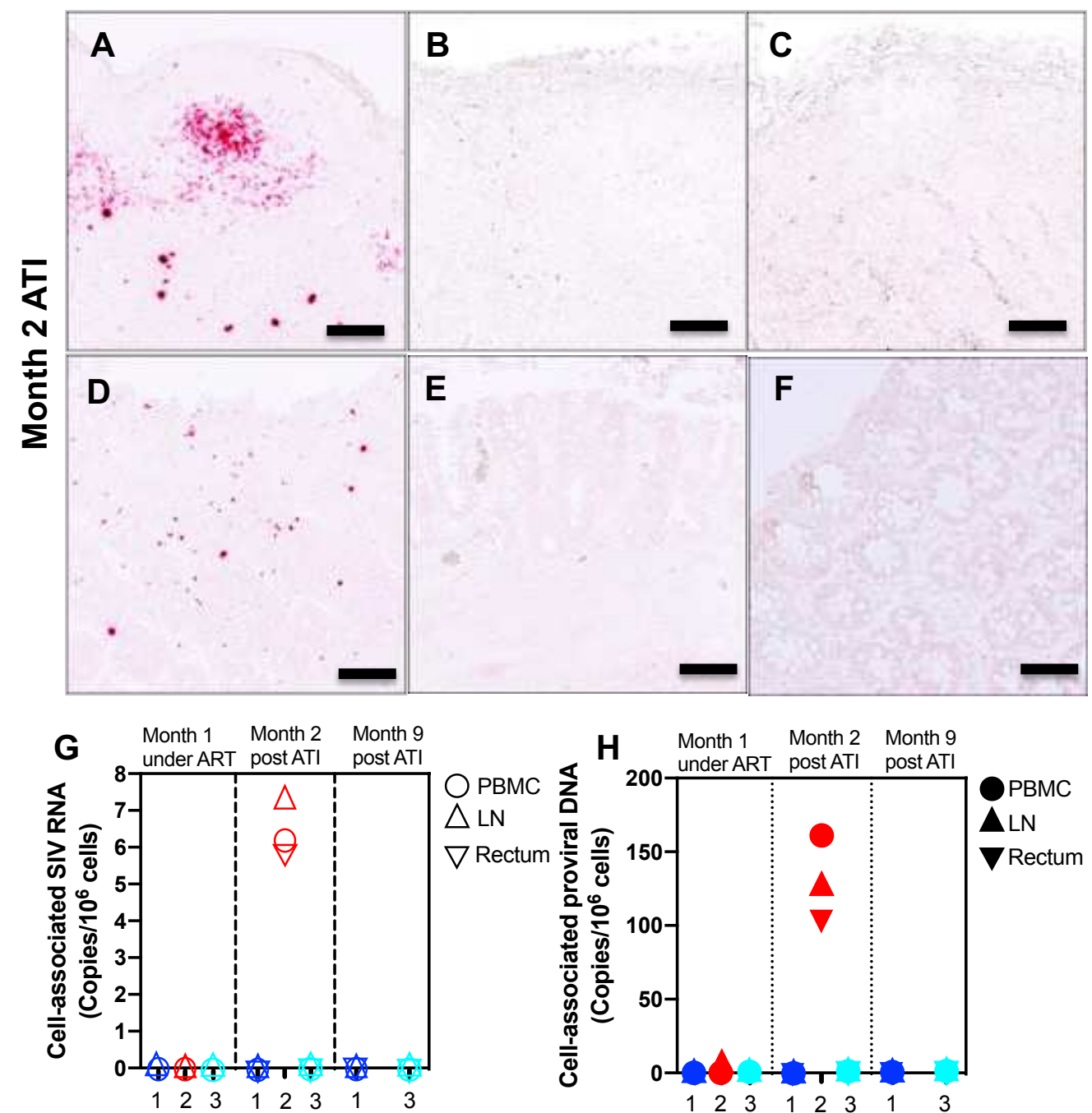

I OPBMC $\diamond$ Spleen $\square$ Jej LPL

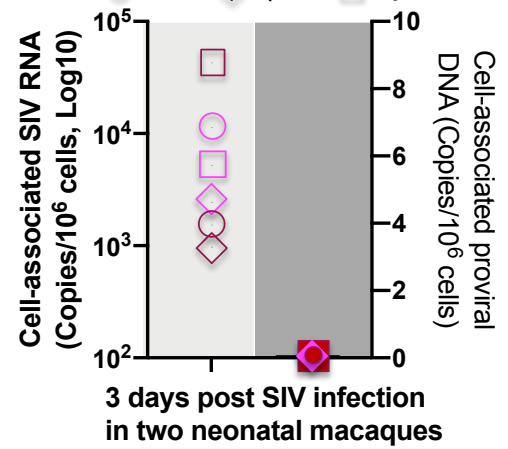

Infant 3

Infant 1

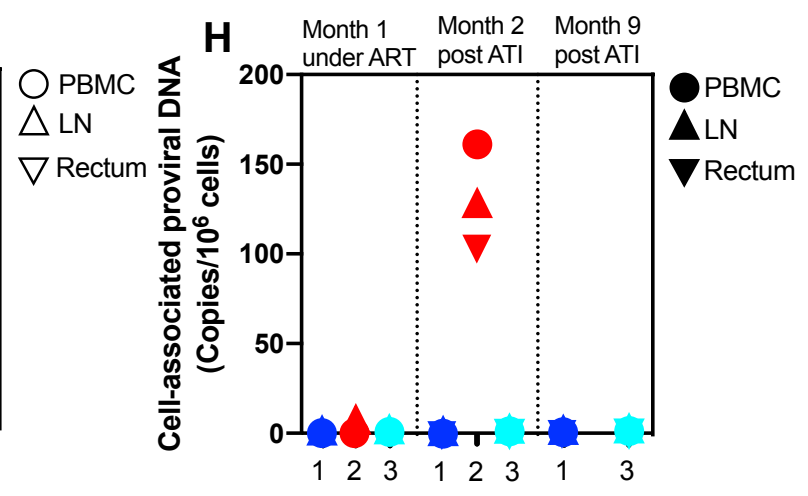

只 $\frac{\emptyset}{1}$

กิ

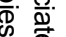

응음

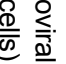

3 days post SIV infection in two neonatal macaques 


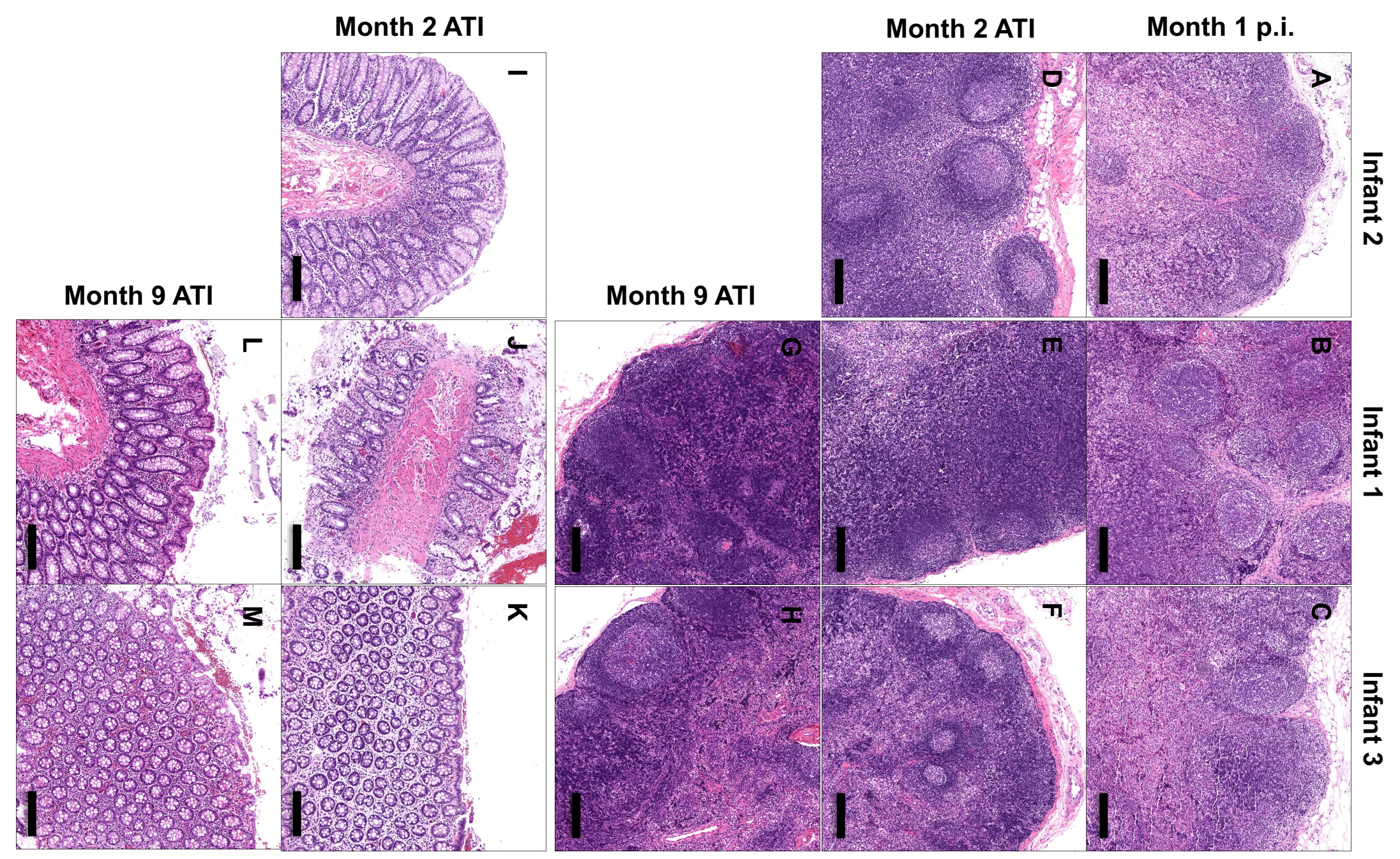

$\frac{T}{\bar{Q}}$
$\stackrel{\underline{T}}{\bar{D}}$
$\omega$ 


\begin{tabular}{|c|c|c|c|c|c|c|c|c|c|c|}
\hline Animal ID & $A^{*} 01$ & $A^{*} 02$ & $A^{*} 08$ & $A * 11$ & $B^{*} 01$ & $B^{*} 03$ & $B * 04$ & $B^{*} 08$ & $B^{*} 17$ & DRB*w201 \\
\hline POS & + & + & + & + & + & + & + & + & + & + \\
\hline NEG & Negative & Negative & Negative & Negative & Negative & Negative & Negative & Negative & Negative & Negative \\
\hline Infant 1 & Negative & + & Negative & Negative & Negative & Negative & Negative & Negative & Negative & Negative \\
\hline Infant 2 & Negative & + & + & Negative & + & Negative & Negative & Negative & Negative & Negative \\
\hline Infant 3 & Negative & + & Negative & Negative & + & Negative & Negative & Negative & Negative & + \\
\hline
\end{tabular}

B
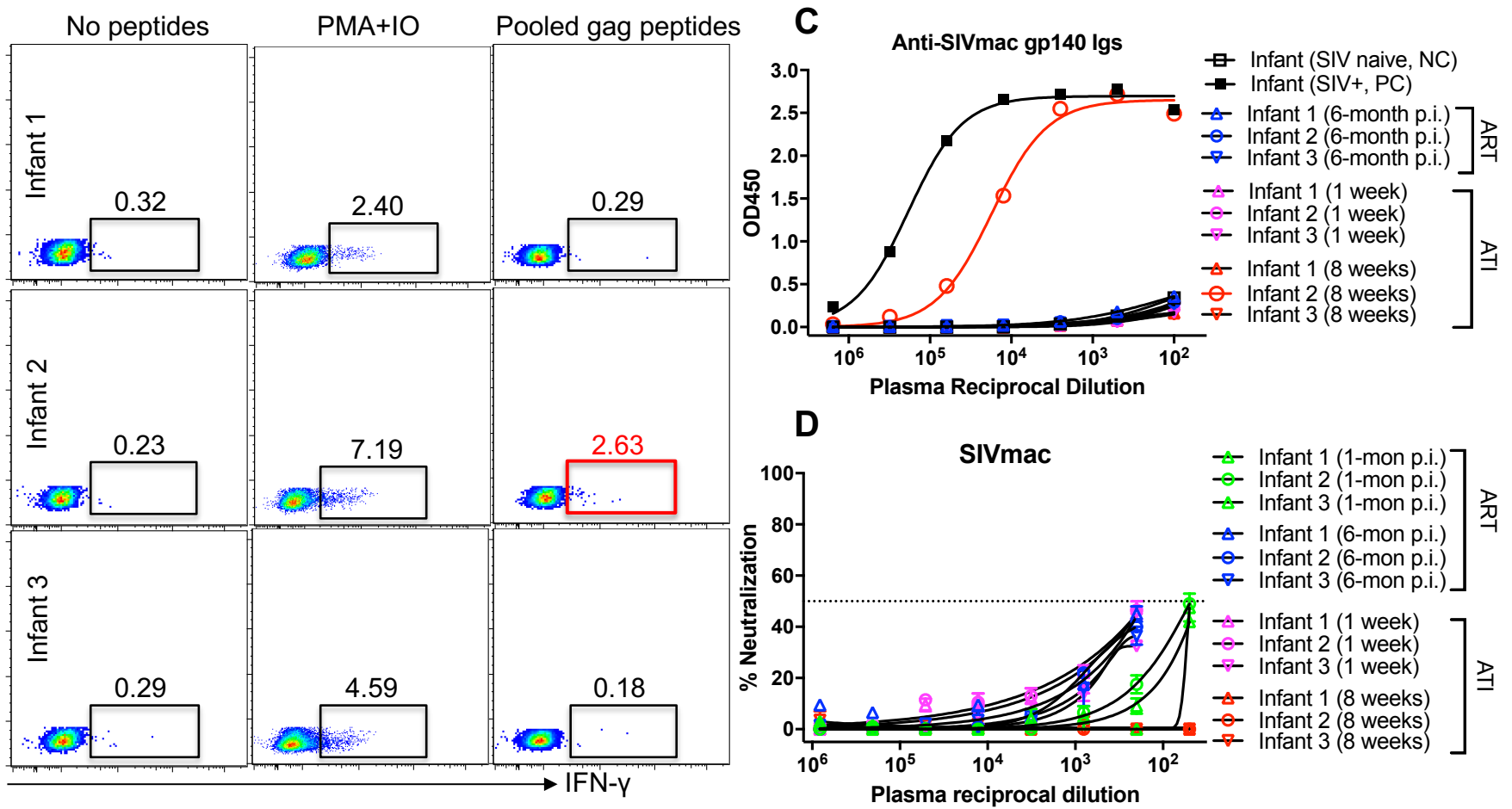

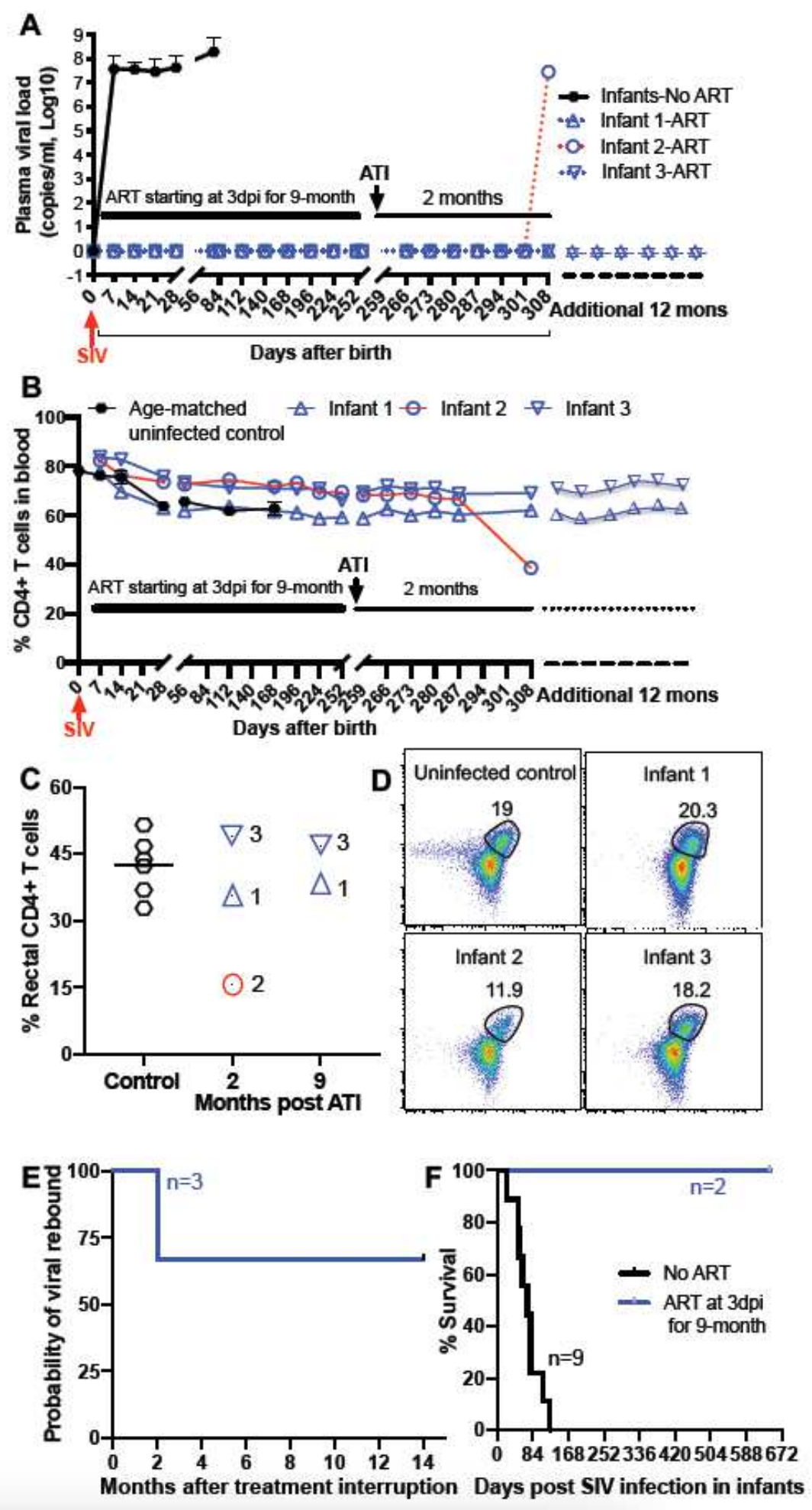

\section{Figure 1}

Virologic and immunologic events in postnatally SIV-infected infant macaques on early ART. (A) Plasma viral load in three infants on ART initiated at $3 \mathrm{dpi}$, compared with that of archived SIV-infected infants without treatment (solid dark line, $n=9$ ). Two infants on early ART showed sustained virologic remission 
up to 14 months until the present after treatment interruption. (B) Changes in peripheral CD4+ T cells in the three experimental infants, compared with those of archived SIV-infected infants without treatment (solid dark line, $n=9$ ). Peripheral CD4+ T cell loss was observed in infant 2 at 2 months post ATI. (C) Changes in rectal CD4+ T cells in three infants at 2-or 9-months post ATI, compared with additional those of age-matched SIV naïve infants with 1-2 years old $(n=6)$. (D) Representative dot plot of central memory CD4+ T cells in the blood of three experimental infants at 2 months post ATI, compared with age-matched SIV naïve control. (E) Months of viral rebound after treatment interruption in postnatally SIV-infected infants when ART is initiated at 3dpi $(n=3)$. (F) Survival of postnatally SIV-infected infants with $(n=2)$ or without $(n=9)$ early ART. The three experimental infants were born on the same day and intravenously inoculated with the same SIV inoculum after birth and received DTG-based ART (TFV/FTC/DTG) initiated at $3 \mathrm{dpi}$ for 9 months. Infant 2 was euthanized at 2 months post ATI when viral rebound was observed. 


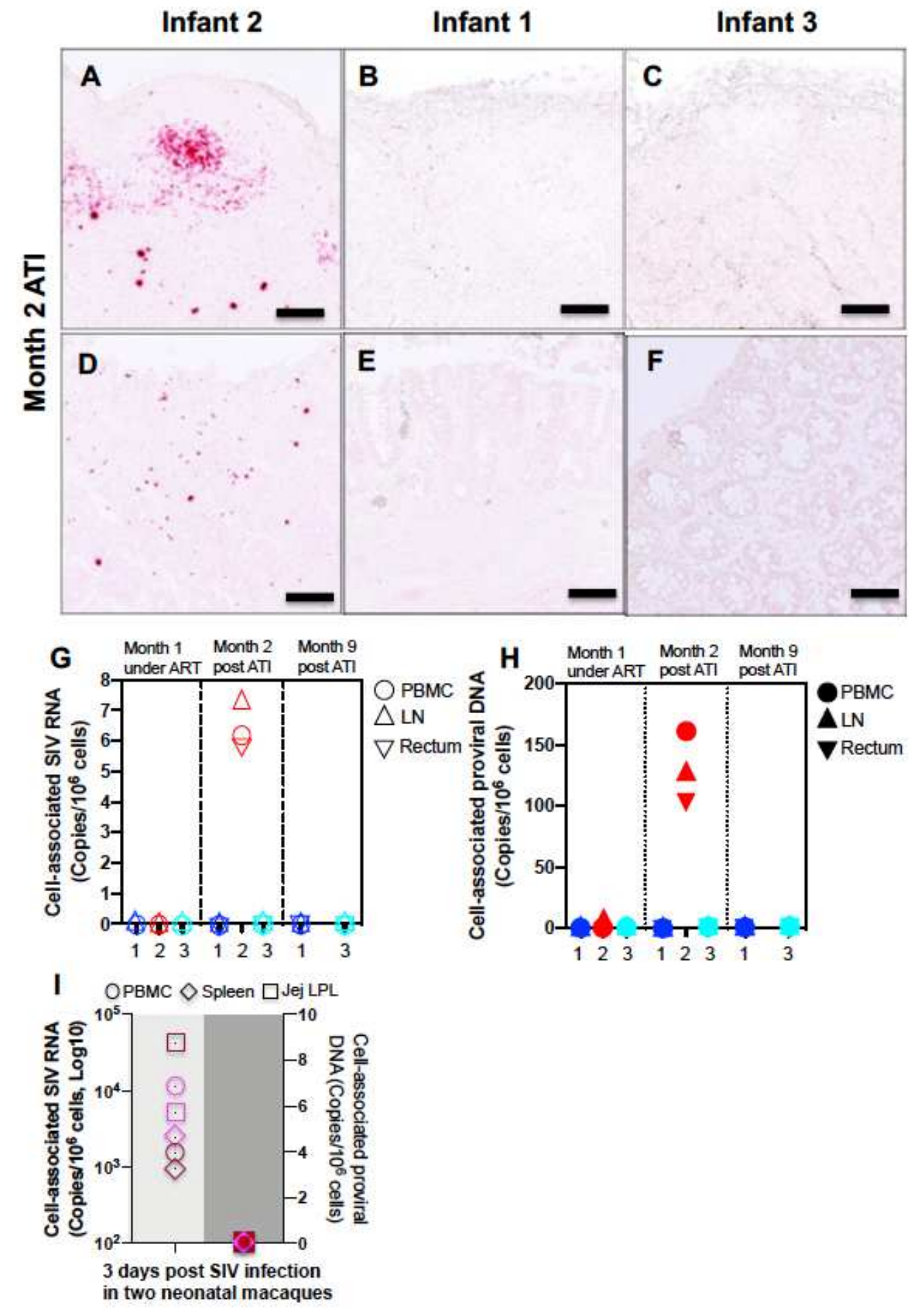

\section{Figure 2}

In situ SIV RNA in LN and rectal biopsies and cell-associated SIV RNA and proviral DNA in postnatally SIV-infected infant macaques on early ART. (A-C) In situ SIV RNA+ cells in LNs in three infants at 2 months post ATI. (D-F) In situ SIV RNA+ cells in rectal tissue biopsies in three infants at 2 months post ATI. SIV RNA was detected in both $L N$ and rectal tissue of only infant 2 at 2 months post ATI (A and D). (G) Levels of cell-associated SIV RNA in PBMCs and LNs at month 1 under ART, or PBMCs, and LN and 
rectal lymphocytes at 2-, 9-months post ATI. $(\mathrm{H})$ Levels of cell-associated SIV integrated proviral DNA in PBMCs and LNs at month 1 under ART, or PBMCs, and LN and rectal lymphocytes at 2-, 9-months post ATI. Notably, very low levels of proviral DNA ( 0.406 copies/million cells) were detected in the LN of only infant 2 but not infants 1 and 3 at month 1 of ART. (I) Levels of cell-associated SIV RNA and proviral DNA in archived PBMCs, spleen and jejunum lamina propria lymphocytes in two additional SIV-infected neonates, who were intravenously infected with SIV at birth without treatment and euthanized at $3 \mathrm{dpi}$. Bar, $100 \mu \mathrm{m}$.

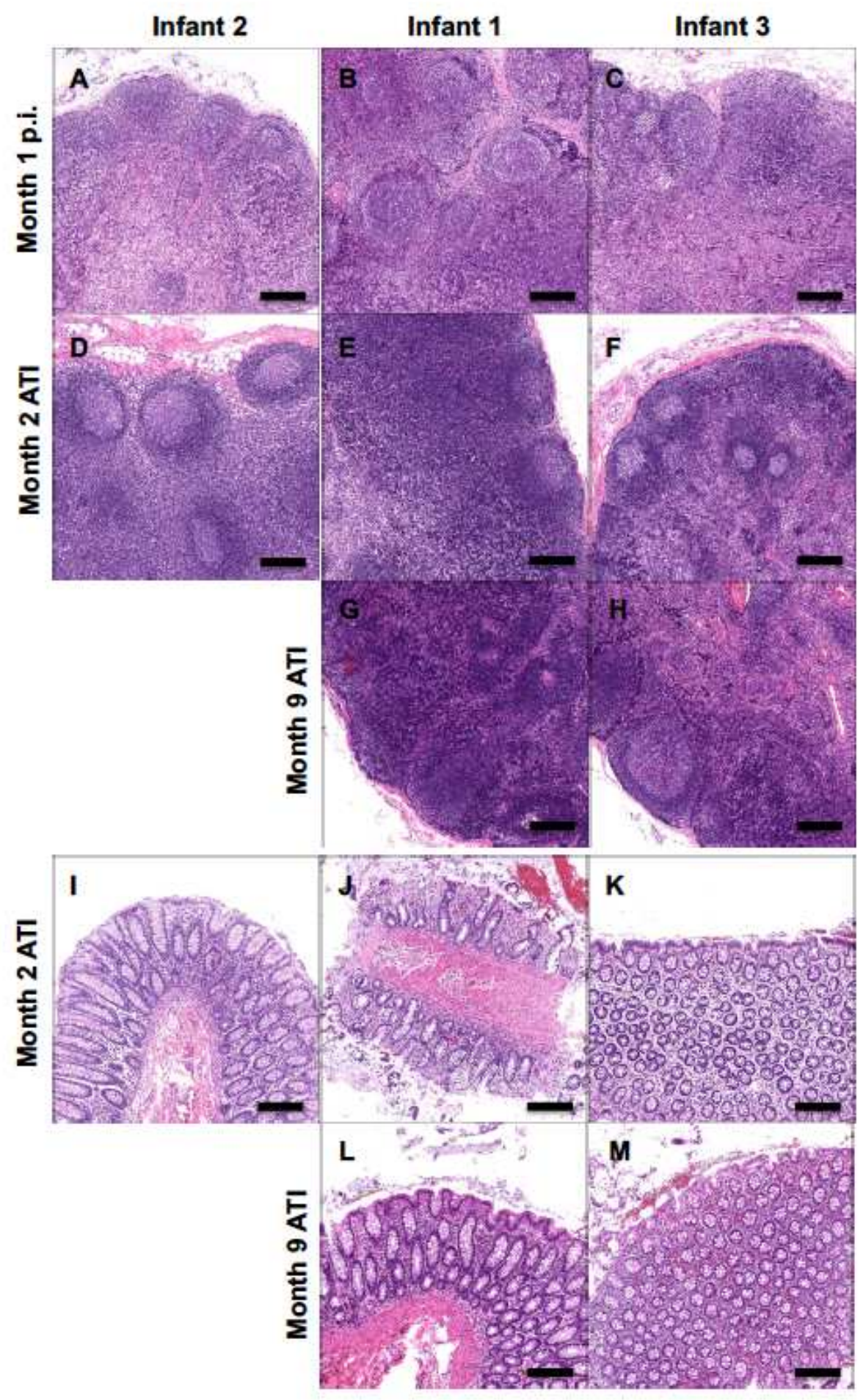




\section{Figure 3}

Histopathological changes of axillary LN and rectal tissues in postnatally SIV-infected infant macaques on early ART. (A-H) H\&E staining of LN in experimental infants at 1 month under ART (A-C), 2- months (DF) or 9-months (G and H) post ATI. (I-M) H\&E staining of rectal tissues in experimental infants at 2 (I-K) or 9 ( $L$ and $M)$ months post ATI. There were no differences among the three infants, except in infant 2 at 1 month under ART, which showed small and limited numbers of germinal centers in the LN and multifocal aggregates of neutrophils in the rectum at month 2 of ATI. Infant 2 was euthanized at 2 months of ATI when viral rebound was observed. Bar, $200 \mu \mathrm{m}$.

\begin{tabular}{|c|c|c|c|c|c|c|c|c|c|c|}
\hline Animal ID & $A^{*} 01$ & $\mathrm{~A}^{*} 02$ & $\mathrm{~A}^{*} 08$ & $A^{* 11}$ & $B^{*} 01$ & $\mathrm{~B}^{*} 03$ & $B^{*} 04$ & B*08 & $B * 17$ & DRB'w201 \\
\hline POS & + & + & + & + & + & + & + & + & + & + \\
\hline NEG & Negative & Negative & Negative & Negative & Negative & Negative & Negative & Negative & Negative & Negative \\
\hline Infant 1 & Negative & + & Negative & Negative & Negative & Negative & Negative & Negative & Negative & Negative \\
\hline Infant 2 & Negative & + & + & Negative & + & Negative & Negative & Negative & Negative & Negative \\
\hline Infant 3 & Negative & + & Negative & Negative & + & Negative & Negative & Negative & Negative & + \\
\hline
\end{tabular}

\section{B}
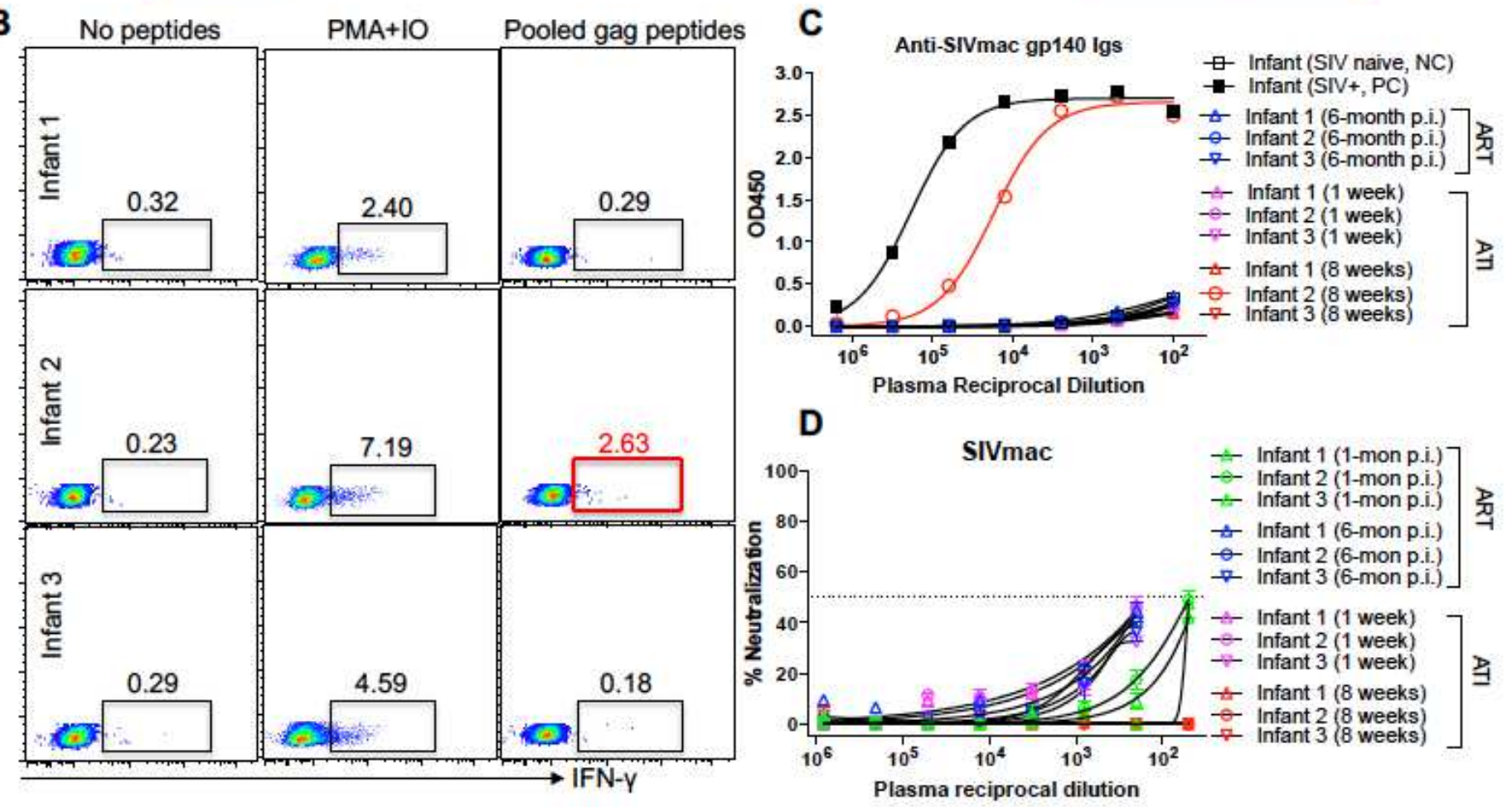

D

Figure 4

SIV Env-specific antibody and SIV gag-specific CTL responses in postnatally SIV-infected infant macaques on early ART. (A) MHC I alleles in the three experimental infants. (B) SIV gag-specific CD8+ T cells in the three infants at 2 months post ATI. (C) Levels of anti-SIV gp140-specific antibodies in the three infants before and after treatment interruption. (D) Levels of neutralizing antibody against SIV Env in the three infants before and after treatment interruption ATI. SIV gag-specific CTLs and anti-SIV Env antibody were detected in only infant 2 at 2 months post ATI when viral rebound was observed. None of the three 
infants had protective $\mathrm{MHC}$ class I alleles (Mamu-B*08, Mamu-A*01, or Mamu-B*17) or exhibited neutralizing antibody responses. 